\title{
The potential use of intralipid to minimize propofol's cardiovascular effects
}

\author{
Ferrante S. Gragasin, MD · Sandra T. Davidge, PhD • \\ Ban C. H. Tsui, MD
}

Received: 30 October 2008/Revised: 11 November 2008/Accepted: 17 November 2008/Published online: 14 January 2009

(C) Canadian Anesthesiologists' Society 2008

\section{To the Editor}

Many reports exist which advocate the use of intralipid to reverse local anesthetic cardiovascular toxicity. The precise mechanism of action, while unknown at the present time, may include a combination of reduced tissue binding of local anesthetic by a plasma-lipid phase and a beneficial metabolic effect involving cardiac mitochondria. ${ }^{1}$ We hypothesized that intralipid can also function as a cardiovascular reversal agent for propofol.

Despite suggestions that physostigmine ${ }^{2}$ or aminophylline 3 can reverse the sedative-hypnotic effects of propofol, no medication currently exists which can directly reverse the cardiovascular effects of propofol. It remains a matter of supportive management while allowing the effects of propofol to dissipate. From a recent study involving aging of resistance systemic arteries ex vivo, we found that vascular relaxation was induced by propofol concentrations between 1 and $100 \mu \mathrm{M}$ (unpublished results). In a similar experiment, we also found that propofol-induced relaxation $\left[100 \mu \mathrm{M}\left(0.02 \mathrm{mg} \mathrm{ml}^{-1}\right.\right.$ final concentration); Novopharm, ON, Canada] was antagonized by the administration of intralipid $20 \%$ at a final concentration of $2-4 \%$ soybean oil (Baxter, ON, Canada). Our method of isolating arteries has been described previously. ${ }^{4}$ Briefly, rat mesenteric arteries $100-200 \mu \mathrm{m}$ in diameter were excised and subjected to isometric tension studies utilizing a wire myograph system. These arteries were pre-constricted with phenylephrine (PE) and were relaxed by propofol. After the addition of

F. S. Gragasin, MD · S. T. Davidge, $\mathrm{PhD}$.

B. C. H. Tsui, MD ( $\square)$

University of Alberta, Edmonton, Canada

e-mail: btsui@ualberta.ca

URL: www.EdmARA.ca propofol $\left(0.02 \mathrm{mg} \mathrm{ml}^{-1}\right.$ final concentration), intralipid $20 \%(500-1,000 \mu \mathrm{l}$ in $5 \mathrm{ml}$ tissue bath) consistently reversed the relaxation caused by propofol in four out of four samples. In contrast, the addition of an equivalent volume of saline (control) did not reverse the propofolinduced relaxation (Fig. 1). Based on these preliminary findings, we extrapolated that approximately $50-100 \mathrm{ml}$ of intralipid $20 \%$ may be required to reverse the effects of $1 \mathrm{ml}$ of commercially available propofol $\left(10 \mathrm{mg} \mathrm{ml}^{-1}\right)$. Additionally, intralipid itself did not induce constriction in the absence of PE and was not toxic to the arteries, since they exhibited PE constriction following intralipid washout.

Propofol is available commercially as a mixture in intralipid, where soybean oil holds the bulk of the propofol. ${ }^{5}$ Therefore, we propose that intralipid can serve as a "propofol mop" by extracting propofol from its site of action (e.g., hydrophobic pockets of membrane proteins). It is unlikely to be a dilutional effect, since the corresponding volume of saline added to the tissue baths did not reverse the vasodilation. We suggest that intralipid may inhibit the untoward effects of propofol at the vascular level, since previous findings have demonstrated that only small amounts of intralipid cross the blood-brain barrier. ${ }^{6}$ Therefore, with the administration of intralipid, the actions of propofol on sedation/consciousness have the potential to be unaltered, without cardiovascular depression. As mentioned above, intralipid is being advocated as an antidote for local anesthetic toxicity, and we propose an additional role to minimize propofol's untoward cardiovascular sideeffects. Similar to treatment for local anesthetic toxicity, further studies taking the bench-to-bedside approach will need to be completed to determine the minimum amount of intralipid necessary to reverse the cardiovascular effects of propofol in vivo. Dose-finding studies utilizing this type of 
Fig. 1 Intralipid, but not an equivalent volume of saline, reverses propofol-induced vasodilation Representative traces for the effects of (a) intralipid $v s$ (b) saline control, and (c) mean data demonstrating reversal of propofol-induced relaxation in resistance mesenteric arteries by the addition of intralipid $(n=4$ per group); $* P<0.05$ intralipid vs control
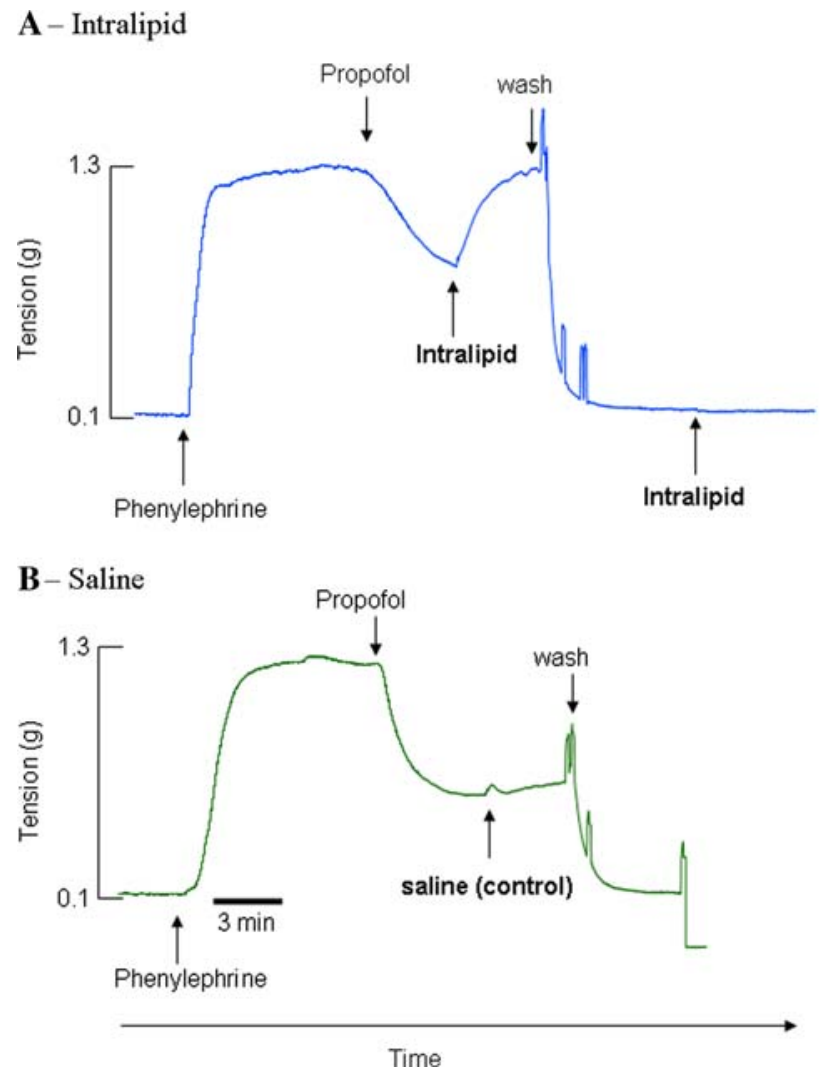

C-Mean Data

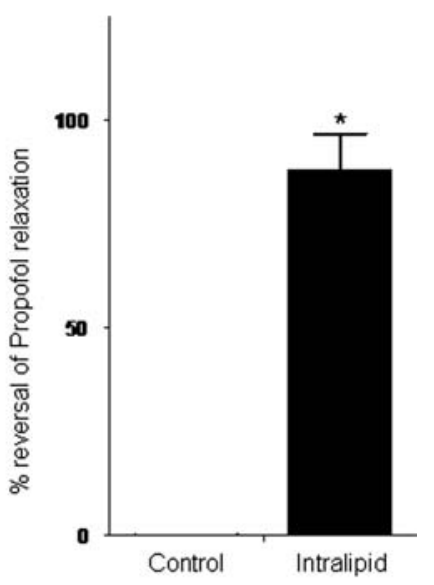

experimental set-up, followed by the use of whole animal models, will be required to address this question.

Conflicts of interest None declared.

\section{References}

1. Weinberg $G$. Lipid rescue resuscitation from local anaesthetic cardiac toxicity. Toxicol Rev 2006; 25: 139-45.

2. Meuret P, Backman SB, Bonhomme V, Plourde G, Fiset P. Physostigmine reverses propofol-induced unconsciousness and attenuation of the auditory steady state response and bispectral index in human volunteers. Anesthesiology 2000; 93: 708-17.

3. Sakurai S, Fukunaga A, Fukuda K, Kasahara M, Ichinohe T, Kaneko $Y$. Aminophylline reversal of prolonged postoperative sedation induced by propofol. J Anesth 2008; 22: 86-8.

4. Arenas IA, Armstrong SJ, Xu Y, Davidge ST. Tumor necrosis factor-alpha and vascular angiotensin II in estrogen-deficient rats. Hypertension 2006; 48: 497-503.

5. Baker MT, Naguib M. Propofol: the challenges of formulation. Anesthesiology 2005; 103: 860-76.

6. Yano T, Nakayama R, Ushijima $K$. Intracerebroventricular propofol is neuroprotective against transient global ischemia in rats: extracellular glutamate level is not a major determinant. Brain Res 2000; 883: 69-76. 